\title{
Analisis Tingkat Kepuasan Pelanggan Menggunakan Fuzzy Mamdani (Studi Kasus: Busrain Bakery)
}

\author{
Ali Ikhwan, Mohammad Badri, Mega Andriani, Nurhadizah Saragih \\ Fakultas Sains dan Teknologi, Universitas Islam Negeri Sumatera Utara
}

\begin{tabular}{|c|c|}
\hline Article Info & " ABSTRACT \\
\hline $\begin{array}{l}\text { Article history: } \\
\text { Received May } 31^{\text {th }}, 2019 \\
\text { Revised June } 12^{\text {th }}, 2019 \\
\text { Accepted Augs } 12^{\text {th }}, 2019\end{array}$ & $\begin{array}{l}\text { Ketatnya kondisi persaingan pasar mengharuskan setiap perusahaan berpacu } \\
\text { supaya tetap eksis di pasar. Agar tetap dapat bertahan dalam persaingan } \\
\text { pasar, perusahaan harus memperhatikan kepuasan pelanggan. Untuk } \\
\text { mengukur kepuasan pelanggan, perusahaan senantiasa harus memperhatikan } \\
\text { rasa makanan dan kualitas pelayanannya. Pengaruh rasa makanan dan } \\
\text { kualitas pelayanan terhadap kepuasan pelanggan di Toko Busrain Bakery } \\
\text { dianalisis menggunakan fuzzy Mamdani dengan bantuan software Matlab. } \\
\text { Untuk mendapatkan output dilakukan beberapa tahapan dalam perancangan } \\
\text { sistem yaitu: pembentukan himpunan fuzzy, aplikasi fungsi implikasi, } \\
\text { komposisi aturan, dan defuzzifikasi. Hasil yang diperoleh dari input yang } \\
\text { diberikan adalah rasa makanan dengan nilai } 8 \text { dan domain [6 10]. Artinya, } \\
\text { variabel rasa makanan enak. Dari input kualitas pelayanan diperoleh nilai } 7 \\
\text { dengan domain [3 7]. Artinya, variabel kualitas pelayanan cukup baik. Dari } \\
\text { input yang diberikan diperoleh output tingkat kepuasan konsumen sebesar } \\
85,96 \% \text { yang berarti bahwa pelanggan puas dengan rasa makanan dan } \\
\text { kualitas pelayanan yang diberikan oleh Toko Busrain Bakery. } \\
\text { Copyright } @ 2019 \text { STMIK Triguna Dharma. } \\
\text { All rights reserved. }\end{array}$ \\
\hline $\begin{array}{ll}\text { First Author } & \\
\text { Nama } & \text { :Ali Ikhwan } \\
\text { Kantor } & \text { :STMIK Triguna Dharma } \\
\text { Program Studi :SistemInformasi } \\
\text { E-Mail } & \text { :Ali_ikhwan@ @insu.ac.id }\end{array}$ & \\
\hline
\end{tabular}

\section{PENDAHULUAN}

Ketatnya persaingan dalam pemasaran juga konsumen yang semakin selektif memilih produk mengharuskan Busrain Bakery selaku toko roti untuk selalu meningkatkan kualitas pelayanannya pada pelanggan. Kepuasan pelayanan merupakan hal yang sangat penting dalam pemasaran. Jika pelanggan puas maka dapat dipastikan toko tersebut menjadi langganannya, sebaliknya ketidakpuasan pelanggan menyebabkan ia beralih ke toko yang lain.

Untuk meningkatkan kualitas pelayanan dan kualitas makanan, harus mengevaluasi pelayanan dan kualitas makanan yang diberikan kepada konsumen sebelumnya, apakah telah sesuai dengan harapan dan keinginan konsumen atau belum. Setelah mengevaluasinya, maka selanjutnya menentukan variabel untuk penilaian kepuasan konsumen/pelanggan kedepan-nya.

Dengan menggunakan logika fuzzy, nantinya akan dihasilkan suatu model fuzzy Mamdani yang dapat menganalisa tingkat kepuasan pelayanan dan kualitas makanan pada pelanggan.

\section{LANDASAN TEORI}

\section{Logika Fuzzy}

Dalam kamus Oxford, istilah fuzzy didefinisikan sebagai blured (kabur atau remang remang), indistinct (tidak jelas), imprecisely defined (didefinisikan secara tidak presisi), confuced (membingungkan), vague (tidak jelas). Kata fuzzy lebih dipandang sebagai sebuah technical adjective dalam teorinya. Yang dimaksud dengan sistem fuzzy adalah sebuah sistem yang dibangun dengan definisi, cara kerja, dan deskripsi yang jelas berdasar pada fuzzy logic. Yang ingin ditekankan disini adalah bahwa meskipun sebuah fenomena yang akan dimodelkan dengan sistem fuzzy adalah bersifat fuzzy, sistem fuzzy yang dibangun untuk memodelkan fenomena tersebut mempunyai definisi cara kerja dan deskripsi yang jelas berdasar pada teori fuzzy logic. 
Secara umum, fuzzy logic adalah sebuah metodologi "berhitung" dengan variabel kata-kata (linguistic variable), sebagai pengganti berhitung dengan bilangan. Fuzzy logic telah menjadi area riset yang mengesankan karena kemampuannya dalam menjembatani bahasa mesin dengan bahasa manusia.

\section{Metode Fuzzy Mamdani}

Metode Fuzzy Mamdani sering dikenal sebagai metode Max-Min. Metode yang dikenalkan oleh Ebrahim Mamdani pada tahun 1975 ini adalah metode yang paling sering digunakan karena metode yang pertama kali dibangun dan berhasil diterapkan dalam rancang bangun sistem kontrol menggunakan teori himpunan fuzzy.

Ada 4 tahapan dalam fuzzy Mamdani untuk mendapatkan output:

a. Pembentukan himpunan fuzzy (fuzifikasi)

Fuzifikasi merupakan proses pengubahan nilai crisp (real) ke nilai fuzzy. Hal ini berguna pada kendali logika fuzzy. Sebab kendali fuzzy hanya dapat mengolah nilai fuzzy. Hal ini juga dapat diterangkan bahwa semua nilai-nilai yang terukur di lapangan tidak sepenuhnya eksak. Untuk memasukkan faktor ketidakpresisian ini bahwa suatu nilai dapat didefiniskan dalam lingkup nilai tertentu. Lingkup nilai tertentu itu dikenal sebagai himpunan fuzzy. Nilai di lapangan akan dinyatakan dalam bentuk data fuzzy yang dinyatakan ke dalam dua aspek, yaitu himpunan fuzzy dengan nilai keanggotaannya.

b. Aplikasi fungsi Implikasi (aturan)

Fungsi implikasi merupakan struktur logika yang terdiri atas kumpulan premis dan satu konklusi. Bentuk dari Fungsi Implikasi adalah:

IF (premis-1) • (premis-2) • (premis-3)

$\bullet . . . . \cdot \bullet($ premis-n) THEN Konklusi

dengan $\bullet$ adalah operator (AND atau OR).

c. Komposisi aturan

Tidak seperti penalaran monoton apabila sistem terdiri dari beberapa aturan, maka inferensi diperoleh dari kumpulan dan korelasi antar aturan. Ada 3 metode yang digunakan dalam melakukan inferensi fuzzy yaitu: Max, additive dan probabilistic OR (probor).

Pada penelitian ini, kami menggunakan metode Max. Penggabungan fungsi keanggotaan dengan menggunakan Metode Max dilakukan dengan menggunakan perumusan:

$\mu_{\mathrm{sf}}=\max \left(\mu_{\mathrm{sf}}\left(\mathrm{x}_{\mathrm{i}}\right), \mu_{\mathrm{kf}}\left(\mathrm{x}_{\mathrm{i}}\right)\right)$

dengan $\mu_{\mathrm{sf}}\left(\mathrm{x}_{\mathrm{i}}\right)$ menyatakan nilai keanggotaan solusi fuzzy sampai aturan ke-i, $\mu_{\mathrm{kf}}\left(\mathrm{x}_{\mathrm{i}}\right)$ menyatakan nilai keanggotaan konsekuensi fuzzy aturan ke-i

\section{d. Defuzzifikasi}

Himpunan fuzzy yang diperoleh dari komposisi aturan-aturan fuzzy merupakan input dari proses defuzzifikasi, sedangkan bilangan pada domain himpunan fuzzy tersebut merupakan output yang dihasilkan. Sehingga jika diberikan suatu himpunan fuzzy dalam range tertentu, maka harus dapat diambil suatu nilai tertentu sebagai output.

Ada beberapa metode defuzzyfikasi pada komposisi aturan, salah satunya adalah Metode Centroid (Composite Moment). Pada metode ini, titik pusat daerah fuzzy diambil untuk memperoleh solusi crisp. Secara umum dirumuskan:

$\mathrm{Z}^{*}=\frac{\int_{z} \mu(z) z d z}{\int_{z} \mu(z) d z}$

dengan $z^{*}$ menyatakan nilai hasil defuzzifikasi, $\mu(\mathrm{z})$ menyatakan nilai keanggotaan, $\operatorname{dan} \int_{\mathrm{z}} \mu(\mathrm{z}) \mathrm{z} \mathrm{dz}$ menyatakan momen untuk semua daerah hasil dari komposisi aturan.

Untuk memperoleh luas setiap daerah hasil komposisi aturan dilakukan dengan cara mencari luas daerah berdasarkan bentuk dari masing-masing hasil komposisi aturan.

\section{METODE PENELITIAN}

Tahap-tahap yang dilakukan dalam penelitian ini adalah mengidentifikasi masalah, melakukan studi literatur, dan mengumpulkan data. Pada tahap identifikasi masalah, permasalahan yang dibahas dalam jurnal ini adalah menganalisis tingkat kepuasan pelanggan berdasarkan pelayanan dan kualitas makanan menggunakan metode Fuzzy Mamdani. Selanjutnya pada tahap studi literatur dan pengumpulan data 
dilakukan studi literatur dari berbagai sumber dan pengumpulan data sekunder dari toko roti Busrain. Untuk mengumpulkan data, diperlukan pula data yang berkualitas yang didapat melalui proses preparation dari data mentah yang dalam prakteknya ditemukan bahwa data cleaning dan preparation membutuhkan usaha total $80 \%$ untuk menjadikannya data yang akurat dan berkualitas sehingga dapat digunakan dalam penelitian. Studi ini meliputi hal-hal dan penyelesaian masalah yang berkaitan dengan Fuzzy Mamdani. Terakhir akan dilakukan penentuan tingkat kepuasan pelanggan terhadap toko roti Busrain.

\section{HASIL DAN PEMBAHASAN}

Studi kasus:

Pemilik toko melihat seorang pelanggan yang datang dan membeli roti di tokonya. Ia ingin melihat seberapa puas pelanggan berbelanja di tokonya. Setelah berbelanja, pelanggan tersebut memberi nilai sebagai berikut. Kualitas pelayanan $=7$

Kualitas makanan $=8$.

Tingkat Kepuasan pelanggan menggunakan 3 aturan fuzzy, yaitu:

[R1] Jika Kualitas Pelayanan tidak baik atau Makanan tidak enak, maka Tingkat kepuasan TIDAK PUAS.

[R2] Jika Kualitas Pelayanan cukup baik, maka tingkat kepuasan CUKUP PUAS.

[R3] Jika Kualitas Pelayanan baik atau Makanan enak, maka tingkat kepuasan PUAS.

\begin{tabular}{|l|l|l|}
\hline \multicolumn{3}{c}{ Membuat Himpunan dan input Fuzzy } \\
\hline fungsi & Variabel & $\begin{array}{l}\text { semesta } \\
\text { pembicaraan }\end{array}$ \\
\hline \multirow{2}{*}{ input } & Kualitas pelayanan & {$\left[\begin{array}{ll}1 & 10\end{array}\right]$} \\
& Kualitas Makanan & {$\left[\begin{array}{ll}1 & 10\end{array}\right]$} \\
\hline output & Tingkat kepuasan $(\%)$ & {$\left[\begin{array}{ll}1 & 100\end{array}\right]$} \\
\hline
\end{tabular}

\begin{tabular}{|c|c|c|}
\hline variabel & $\begin{array}{l}\text { Himpunan } \\
\text { Fuzzy }\end{array}$ & Domain \\
\hline $\begin{array}{l}\text { Kualitas } \\
\text { pelayanan }\end{array}$ & $\begin{array}{l}\text { Tidak Baik } \\
\text { Cukup Baik } \\
\text { Baik }\end{array}$ & 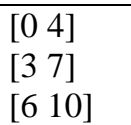 \\
\hline $\begin{array}{l}\text { Kualitas } \\
\text { Makanan }\end{array}$ & $\begin{array}{l}\text { Tidak enak } \\
\text { Enak }\end{array}$ & $\begin{array}{l}{\left[\begin{array}{ll}0 & 5\end{array}\right]} \\
{\left[\begin{array}{ll}6 & 10\end{array}\right]}\end{array}$ \\
\hline $\begin{array}{l}\text { Tingkat } \\
\text { kepuasan } \\
(\%)\end{array}$ & $\begin{array}{l}\text { Tidak Puas } \\
\text { Cukup puas } \\
\text { Puas }\end{array}$ & $\begin{array}{l}{\left[\begin{array}{ll}0 & 35\end{array}\right]} \\
{\left[\begin{array}{ll}35 & 65\end{array}\right]} \\
{\left[\begin{array}{ll}65 & 100\end{array}\right]}\end{array}$ \\
\hline
\end{tabular}

Input Kualitas Pelayanan

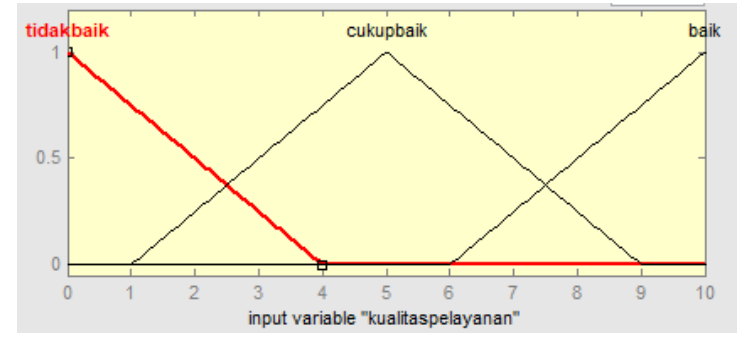

Nilai pelayanan $=7$, maka: $\mu_{\text {tidakbaik }}[7]=0$

$$
\begin{aligned}
& \mu_{\text {cukupbaik }}[7]=\frac{c 1-x}{a 1-b 1}=\frac{9-7}{9-5}=0,5 \\
& \mu_{\text {baik }}[7]=\frac{x-a 2}{b 2-a 2}=\frac{7-6}{10-6}=0,25
\end{aligned}
$$

Input Kualitas Makanan 


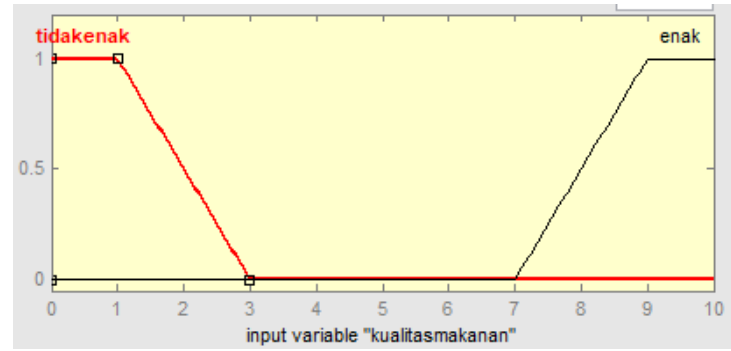

Input nilai makanan= 8, maka:

$\mu_{\text {tidakenak }}[8]=0$

$\mu_{\text {enak }}[8]=\frac{x-a}{b-a}=\frac{g-7}{9-7}=0,5$

Menerapkan Operator Fuzzy

Aturan 1:

Jika Kualitas Pelayanan Tidak Baik atau Makanan Tidak Enak maka Tingkat kepuasan TIDAK PUAS.

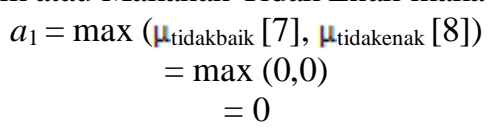

Aturan 2:

Jika Kualitas Pelayanan Cukup Baik maka tingkat kepuasan CUKUP PUAS.

$$
a_{2}=\mu_{\text {cukupbaik }}[7]=0.5
$$

Aturan 3:

Jika Kualitas Pelayanan Baik atau makanan Enak maka tingkat kepuasan PUAS.

$$
\begin{gathered}
a_{3}=\max \left(\mu_{\text {baik }}[7], \mu_{\text {enak }}[8]\right) \\
=\max (0.25,0.5) \\
=0.5
\end{gathered}
$$

Menerapkan Fungsi Implikasi

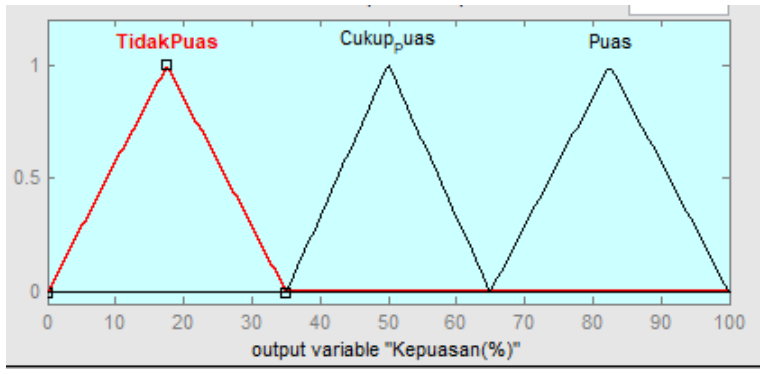

$$
= \begin{cases}0, & x \leq a \text { atau } x \geq c \\ \frac{x-a}{b-a} & a \leq x \leq b \\ \frac{c-x}{c-b} & b \leq x \leq c\end{cases}
$$

$\mu_{\text {tidakpuas }}$

$= \begin{cases}0, & x \leq a \text { atau } x \geq c \\ \frac{x-a}{b-a} & a \leq x \leq b \\ \frac{c-x}{c-b} & b \leq x \leq c\end{cases}$

$\mu_{\text {CukupPuas }}$ 
$= \begin{cases}\frac{0}{x-a} & x \leq a \text { atau } x \geq c \\ \frac{b-a}{c-x} & a \leq x \leq b \\ \frac{c-b}{c} & b \leq x \leq c\end{cases}$

$\mu_{\text {puas }}$

Aturan 1:

$\alpha_{1}=0$, maka tidak ada daerah hasil implikasi

Aturan 2:

$\alpha_{2}=0.5$

$0.5=\frac{x-75}{50-8.5}, x=42.5$

atau

$0.5=\frac{65-x}{65-50}, \quad \mathrm{x}=57.5$

Aturan 3:

$\alpha 3=0.5$

$0.5=\frac{x-65}{82.5-65}, \quad \mathrm{x}=73.75$

atau

$0.5=\frac{100-x}{100-02.5} \quad, \quad \mathrm{x}=91.25$

Mengkomposisikan semua output

$$
\mu_{\mathrm{SF}[\mathrm{z}]}=\left\{\begin{array}{cl}
0, x \leq 35 \text { atau } x \geq 100 \\
\frac{x-35}{50-35}, 35 \leq x \leq 42.5 \\
0.5, x 2.5 \leq x \geq 57.5 \\
\frac{65-x}{65-50}, 57.5 \leq x \leq 65 \\
\frac{x-65}{92.5-65}, 65 \leq x \leq 73.75 \\
0.5,73.75 \leq x \geq 91.25 \\
\frac{100-x}{100-92.5}, 91.25 \leq x \leq 100
\end{array}\right.
$$

Defuzzyfikasi

Menghitung luas daerah:

$\frac{(57,5-42,5)+(65-35)}{2} \times 0,5$

$\mathrm{A} 1=$

$=11,25$

$\frac{(91,25-7275)+(100-65)}{2} \times 0,5 \mathrm{~A} 2=$

$=13,125$

Sederhanakan fungsi komposisi menjadi:

$\mu_{\mathrm{SF}[\mathrm{z}]}=\left\{\begin{aligned} 0, x \leq 35 \text { atau } x \geq 100 \\ 0.06 x-2.3,35 \leq x \leq 42.5 \\ 0.5,42.5 \leq x \geq 57.5 \\ 4.3-0.06 x, 57.5 \leq x \leq 65 \\ 0.05 x-3.7,65 \leq x \leq 73.75 \\ 0.5,73.75 \leq x \geq 91.25 \\ 5.7-0.05 x, 91.25 \leq x \leq 100\end{aligned}\right.$

Menghitung Momen:

$\int_{35}^{42,5}(0,06 z-2,3) z d z$ 
$\mathrm{M} 1=$

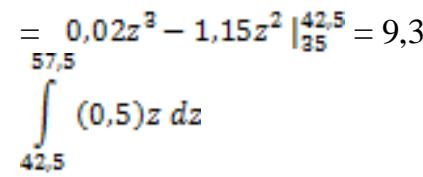

$\mathrm{M} 2=$

$=0,\left.5 z^{2}\right|_{42,5} ^{57,5}=375$

$\int_{57,5}^{65}(4,3-0,06 z) z d z$

$\mathrm{M} 3=$

$=\left.\left(2,15 z^{2}-0,02 z^{2}\right)\right|_{57,5} ^{65}=285$

$\int_{65}(0,05 z-3,7) z d z$

M4 =

$=\left(0.016 z^{3}-1,\left.85 z\right|_{65} ^{7 a, 75}=-221,92\right.$

91.25

$\int_{72,5}(0,5) z d z$

M5 =

$=\left(\left.0.25 z^{2}\right|_{72,75} ^{91,25}=721,875\right.$

100

$(5,7-0,05 z) z d z$

91.25

M6 =

$=\left.\left(2,85 z^{2}-0,016 z^{2}\right)\right|_{78,75} ^{91,25}=926,07$

Menghitung titik pusat (centroid)

$z^{*}=\frac{(M 1+M 2+M 3+M 4+M 5+M 6)}{(A 1+A 2)}$

$=\frac{\left(9,3+375+285-221_{s} 92+721_{v} 875+926,07\right)}{\left(13_{s} 125+11_{s} 25\right)}$

$=\frac{2095,325}{24 \cdot 375}=85,96 \%$

\section{KESIMPULAN DAN SARAN}

Dalam metode fuzzy Mamdani, ada 4 tahapan yang harus dilakukan untuk mendapatkan output, yaitu: 1.Pembentukan himpunan fuzzy (fuzzifikasi)

2. Aplikasi fungsi implikasi (aturan)

3. Komposisi aturan

4. Defuzifikasi. 
Dalam Metode Fuzzy Mamdani, penarikan kesimpulan dapat mudah dimengerti oleh manusia. Oleh karena itu, metode ini dapat menghasilkan keputusan terbaik karena sesuai dengan naluri manusia.

Hasil yang diperoleh dari input yang diberikan adalah rasa makanan dengan nilai 8 dengan domain [6 10]. Artinya, variabel rasa makanan enak. Dari input kualitas pelayanan diperoleh nilai 7 dengan domain [3 7]. Artinya, variabel kualitas pelayanan cukup baik. Dari input yang diberikan diperoleh output tingkat kepuasan konsumen sebesar $85,96 \%$ yang berarti bahwa pelanggan puas dengan rasa makanan dan kualitas pelayanan yang diberikan oleh Toko Busrain Bakery.

\section{DAFTAR PUSTAKA}

Djunaidi, Much dkk. 2005. "Penentuan Jumlah Produksi Dengan Aplikasi Metode Fuzzy Mamdani”. Jurnal Ilmiah Teknik Industri. Vol. 4, No. 2, Hal 95-104.

Ginting, Raheliya. 2014. Analisis Fungsi Implikasi Max-Min dan Max-Prod Dalam Pengambilan Keputusan. Citec Journal. Vol. 1, No. 2. Hal 128-138.

Handoyo, Samingun dan Ari Purwanto S P. 2017. Sistem Fuzzy Terapan dengan Software R. Malang: UBPress.

Ikhwan, Ali dkk. 2015. "Penerapan data mining dengan algoritma Fp-Growth untuk mendukung Strategi Promosi Pendidikan (Studi Kasus Kampus STMIK Triguna Dharma)”. Jurnal Ilmiah Saintikom. Vol.14, No.3. Hal 211-226.

Irawan, Muhammad Dedi. 2017. "Sistem Pendukung Keputusan Menentukan Matakuliah Pilihan pada Kurikulum Berbasis KKNI Menggunakan Metode Fuzzy Sugeno”. Jurnal Media Informasi. Vol. 13, No. 1. Hal. 27- 35.

Kumar, S. Swapna dan Lenina S V B. 2016. Matlab-Easy Way of Learning. New Delhi: Rimjhim House. Naba, Agus. 2009. Tutorial Cepat \& Mudah Fuzzy Logic dengan MATLAB. Jakarta: ANDI . Pusadan, Mohammad Yazdi. 2014. Pemrograman MATLAB pada Sistem Pakar Fuzzy. Yogyakarta: Deepublish.

Rusli, Muhammad. 2017. Dasar Perancangan Kendali Logika Fuzzy. Malang: UB Media. Sihotang, Sunarsan dkk. 2017. "Fuzzy Logic Untuk Menentukan Penjualan Rumah dengan Metode Mamdani (Studi Kasus: PT Gracia Herald)”. Jurnal ISD. Vol. 2, No.2. Hal. 91-101 